\title{
44408 - THE EFFICACY OF SIMULATION-BASED EDUCATION IN REDUCING HUMAN ERROR
}

\author{
Pamela Morgan, Women's College Hospital, Toronto, ON, Canada; \\ Jordan Tarshis, Sunnybrook Health Sciences Centre; \\ Jodi Herold-McIlroy, The Wilson Centre; \\ D Cleave-Hogg, The Wilson Centre; \\ JA Law, Queen Elizabeth II Health Sciences Centre;
}

INTRODUCTION: Research into adverse events in hospitalized patients has suggested that a significant number are potentially preventable. (1) The purpose of this randomized, controlled study was to determine if simulation-based education could decrease anesthesiologist errors in the management of high-fidelity simulation scenarios.

METHODS: After REB approval, anesthesiologists from 5 provinces were recruited. Subjects were randomly assigned to 1 of 3 groups using computer-generated randomization: simulation debriefing; provision of literature about error in medicine; or control and secondary randomization to one of two standardized, validated scenarios. Six to nine months later, subjects returned to manage the alternate scenario.

On the session day, subjects received an orientation, patient information and were given time to prepare the operating room. Actors filled the roles of nurses and surgeon. Performances were videotaped. Faculty facilitators familiar with study objectives but blinded to study group allocation completed performance checklists developed in a previous study, a Global Rating Scale of Performance (GRS) (2) and a Human Factors Rating Scale (HFRS) prior to debriefing. Following the session, Group 1 received an immediate debriefing, Group 2 received literature and the control group was dismissed. Repeated measures analysis of variance (ANOVA) determined the effect of intervention on change in performance and one-way ANOVA to ensure no pre-existing differences in pretest scores between groups.

RESULTS: Sixty-seven subjects were recruited, with 58 complete data sets available. Two subjects' data couldn't be used due to simulator malfunction, 2 couldn't schedule the second session within 6-9 months, and 5 didn't return for a second session. There were no statistically significant differences between Groups 2 and 3 ,so this data was collapsed into a single group $(n=34)$ for comparison with Group $1(n=24)$. There was no significant effect of group on pretest scores for the three performance measures. Repeated measures ANOVA showed a significant improvement between pre and posttest scores on the performance checklist in subjects receiving simulation debriefing $(\mathrm{F} 1,56=5.36)$. Table 1 . There were no significant differences between groups for the HFRS or GRS.

DISCUSSION: This is the first randomized, controlled study in the literature to demonstrate that a high-fidelity simulation experience, with facilitator debriefing, improves performance of practicing anesthesiologists, as evaluated in the simulation setting using a valid, reliable tool. The results of this study provide the groundwork for others to implement simulation-based education to decrease human error. 


\section{REFERENCES:}

1. Can Med Assoc J 2004; 170: 1678-86

2. Br J Anaesth 1994; 73: 293-7

\begin{tabular}{|l|l|l|l|l|l|}
\hline Source & $\begin{array}{l}\text { Degrees of } \\
\text { Freedom }\end{array}$ & $\begin{array}{l}\text { Sum of } \\
\text { Squares }\end{array}$ & $\begin{array}{l}\text { Mean } \\
\text { Square }\end{array}$ & F & $\begin{array}{l}\text { P- } \\
\text { value }\end{array}$ \\
\hline $\begin{array}{l}\text { Between } \\
\text { Subjects } \\
\text { Factor }\end{array}$ & & & & & \\
\hline $\begin{array}{c}\text { Group 1 } \\
\text { versus 2/3 }\end{array}$ & 90.62 & 90.62 & 0.92 & .34 & .34 \\
\hline Error & 5544.14 & 99.00 & & & \\
\hline $\begin{array}{l}\text { Within } \\
\text { Subjects } \\
\text { Factor }\end{array}$ & & 28.72 & 0.79 & .38 & .38 \\
\hline Time & 28.72 & 195.86 & 5.36 & .02 & .02 \\
\hline $\begin{array}{c}\text { Time x } \\
\text { Group 1 } \\
\text { versus 2/3 }\end{array}$ & 195.86 & & & & \\
\hline Error & 2046.57 & 36.55 & & & \\
\hline
\end{tabular}

